\title{
Correction to: Combined use of calcium nitrate, zeolite, and anion exchange resin for controlling phosphorus and nitrogen release from sediment and for overcoming disadvantage of calcium nitrate addition technology
}

Yanhui Zhan ${ }^{1} \cdot$ Xiaolong $\mathrm{Wu}^{1} \cdot$ Jianwei Lin ${ }^{1}$

Published online: 19 May 2020

(C) Springer-Verlag GmbH Germany, part of Springer Nature 2020

Correction to: Environmental Science and Pollution Research https://doi.org/10.1007/s11356-020-08850-w

The correct presentation fig. $8 \mathrm{a}$ is presented in this paper.

The original article is corrected.

Fig 8 a Reduction rate of PO-water NO3--N by AERN-contained floating system; b reduction efficiencies of PO-water NH4 +-N by Ca(NO3)2/ zeolite, and $\mathrm{Ca}(\mathrm{NO} 3) 2 /$ zeolite/AERN methods
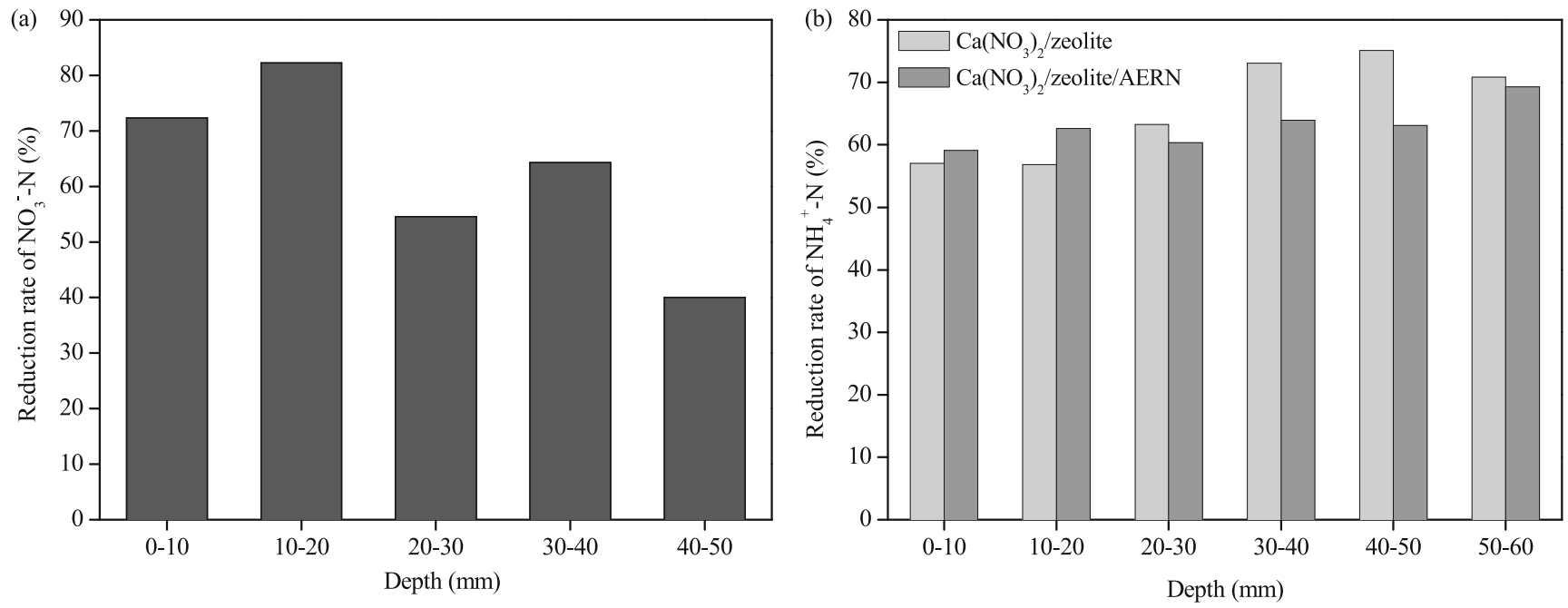

The online version of the original article can be found at https://doi.org/ $10.1007 / \mathrm{s} 11356-020-08850$-w

Jianwei Lin

jwlin@ shou.edu.cn

1 College of Marine Ecology and Environment, Shanghai Ocean

University, Hucheng Ring Road No. 999, Shanghai 201306, China 